\title{
Severe asthma: phenotyping to endotyping or vice versa?
}

\author{
Alberto Papi (i] ${ }^{1}$, Marina Saetta ${ }^{2}$ and Leonardo Fabbri $\mathbb{1}^{3}$
}

Affiliations: ${ }^{1}$ Research Centre on Asthma and COPD, Department of Medical Sciences, University of Ferrara, Ferrara, Italy. ${ }^{2}$ Department of Cardiac, Thoracic, and Vascular Sciences, University of Padova, Padova, Italy. ${ }^{3}$ Department of Medicine Endocrinology Geriatrics and Metabolism, University of Modena Reggio Emilia, Modena, Italy.

Correspondence: Alberto Papi, Research Centre on Asthma and COPD, Department of Medical Sciences, University of Ferrara, Italy, Via Rampari di S. Rocco, 27 - 44121 Ferrara, Italy. E-mail: ppaQunife.it

@ERSpublications

Molecular rather than clinical phenotyping of airway inflammation might be used in the treatment of severe asthma http://ow.ly/9Kba308jaXX

Cite this article as: Papi A, Saetta M, Fabbri L. Severe asthma: phenotyping to endotyping or vice versa? Eur Respir J 2017; 49: 1700053 [https://doi.org/10.1183/13993003.00053-2017].

The most recent definition of asthma is that it is a heterogeneous disease, usually characterised by chronic airway inflammation, defined by a history of chronic respiratory symptoms that vary over time, both in frequency and intensity, and associated with variable airflow limitation [1]. Admittedly, asthma is used as an umbrella term, like anaemia, arthritis and cancer. This highlights the importance of taking an individualised approach to a patient's diagnosis and management, using genomics, proteomics, and "humanomics" as emphasised in the GINA guidelines [2]. The vague definition reflects our poor understanding of the underlying mechanisms of the disease, particularly of its more severe expressions. In the guidelines, they are included in steps 4 and 5 of treatment. This might imply that so-called severe asthma is at the extreme of a continuum of severity, something which has never been demonstrated in prospective studies. In contrast to this concept are the observations that: 1) the vast majority of asthmatics $(>95 \%)$ are treatable [1] and have little if any excessive risk of progression or death [3]; 2) severe asthma improves through intervention on modifiable risk factors [4], particularly because of its undertreatment [1,5]; and 3) mortality for asthma is not increased nor increasing [6, 7]. Nonetheless, severe asthma is a major health and social burden, even in childhood and adolescence $[1,8]$.

Notably, several international panels and reviews have provided definitions of severe asthma [9-13], all pointing to one main characteristic: severe refractory asthma remains active and requires all anti-asthma medications recommended for steps 4 and 5, including systemic corticosteroids and anti-IgE $[1,10,11]$.

A major problem in the studies of so-called severe asthma is the heterogeneity of the disease and the difficulty in defining different clinical asthma phenotypes, which has so far hindered the collection of adequate information on underlying mechanisms. There is also significant overlap across clinical clusters, inflammatory profiles, and inflammatory mechanisms [1, 14-18]. Severe asthma is likely to represent several endotypes (subtypes of disease defined by a molecular mechanism), each associated with distinct clinical features, divergent underlying molecular mechanisms, and individual treatment responses endotypes that still need to be defined. Furthermore, although severe asthma can be classified into different phenotypes based on age of onset, atopy, and other parameters determined by clinical, immunological and molecular assessments $[1,12,15-18]$, the stability and natural history of these clinical phenotypes are poorly understood. In some cases, severe asthma seems to be severe from the beginning, both in children and adults, while in other cases an event such as viral infection changes a mild asthma

Received: Jan 102017 | Accepted after revision: Jan 232017

Conflict of interest: Disclosures can be found alongside this article at erj.ersjournals.com

Copyright OERS 2017 
phenotype to a much more severe one. Long-term progression from mild to severe asthma seems to be uncommon.

Kuo et al. [19], authors of a paper published in this issue of the European Respiratory Journal, have examined subjects recruited with the entry criteria for Unbiased Biomarkers for the Prediction of Respiratory Disease Outcomes (U-BIOPRED), a pan-European public-private collaboration funded by the European Commission's Innovative Medicines Initiative [10, 18]. Although the authors have already reported clinical and pathological clustering analyses [15], and found four phenotypes not much different from those previously reported [20,21], they reasoned that clustering severe asthma using clinical features may not only not provide a precise definition of severe asthma, but may even preclude the collection of adequate information on the underlying mechanisms of each phenotype. Indeed, significant overlap of inflammatory profiles and inflammatory mechanisms is present across clinical clusters.

Thus, Kuo et al. [19] tried a new approach to the study of possible endotypes, exploring the driving mechanisms of the various inflammatory profiles by clustering differentially expressed genes in the sputum cells of eosinophilic versus noneosinophilic moderate-to-severe asthmatics from the U-BIOPRED cohort. With this approach they were able to define three transcriptome-associated clusters (TACs): TAC 1, an interleukin (IL)-13/T-helper (Th)2-high predominantly eosinophilic cluster; and TAC 2 and TAC 3, both non-Th2 phenotypes characterised by association with interferon (IFN)/tumour necrosis factor- $\alpha$ (TNF- $\alpha$ )/inflammasome (TAC 2) and metabolic and mitochondrial pathways (TAC 3). Not surprisingly, eosinophilic asthma was almost exclusively present in TAC 1 (but also significantly present in TAC 3), whereas neutrophilic asthma was predominantly associated with TAC 2, and paucigranulocytic asthma was mainly present in TAC 3. In addition to overlapping sputum eosinophilia, biomarkers such as exhaled nitric oxide (eNO) and periostin were no different in the three TACs [22, 23].

These results shed further light on the molecular phenotypes of severe asthma. The findings are indeed novel: Kuo et al. [19] have identified two molecular phenotypes that contain non-Th2 signatures and one that contains Th2 signatures. Also, they showed that molecular phenotypes are characterised not only by one pathway but by several.

While this approach is new and interesting, Kuo et al. [19] acknowledge that it has limitations. Because of the size and selection of the subpopulation of asthmatics (only those capable of producing readable sputum), the limited number of control subjects, and the lack of correlation with multiple clinical, biological and translational data and pathological features, the study should be considered exploratory and hypothesis generating. In particular, the results must be considered specific for the type of patients examined, because in some respects they are a selected subgroup of the U-BIOPRED cohort $[15,18]$. The study could possibly be extended by separately analysing, e.g., smokers and nonsmokers, considering the importance of overlap between asthma and chronic obstructive pulmonary disease [24], selecting patients with different ages of onset, or simply comparing gene profiles in adult-onset severe asthma with those in childhood-onset severe asthma.

As the study compared eosinophilic to noneosinophilic subjects, it will eventually mainly reveal Th2 and non Th2 genes. It would be important to revisit the clinical phenotype recently identified from the U-BIOPRED cohort [15] and assess the consistency/concordance with the transcriptomic clusters reported here and evaluate their clinical relevance. A possible validation would be to show differences in outcomes among the three TAC groups in a validation set. Ideally, because of the sophisticated bioinformatic approaches to the identification of gene and protein expression, it would be interesting to perform a similar bioinformatic analysis of the clinical features to identify the even fewer subjects in whom the profiles match precisely. The lesson from recently advanced therapies has clearly showed us that some monoclonal antibodies (e.g., anti-IL-5) work only in highly selected subgroups and only for selected outcomes (e.g., exacerbations, not symptoms or lung function) [25-27].

A Th2 pattern and eosinophilia may be present in mild, moderate and severe asthma, but the underlying mechanisms could be potentially very different, particularly if the subjects respond differently to treatment [28-30]. One of the limitations of the Kuo et al. [19] study is that the clustering of differentially expressed genes was conducted by pre-selecting genes in eosinophilic versus noneosinophilic sputum from both severe and moderate asthmatics on the assumption that the mechanisms of eosinophilia could be the same. As shown in the study (e.g. figure 3), there is still significant overlap in Th2 and Th1 gene signatures, even within the eosinophilic TAC 1 group. Possibly, it is the association with factors and cytokines working with and potentiating the Th2 profile that makes the difference between clusters with overlapping gene expression. Th1 and other factors may potentiate IL-4, IL-5, and IL-13, thus promoting asthma severity and steroid resistance [28, 29]. This would make it possible for Th2 cytokines in severe asthma to be synergised with other cytokines and mediators, which would affect other target cells such as mast cells, eosinophils, epithelial cells and smooth muscle and result in poor lung function, disease severity, and, more importantly, treatment resistance, a feature not seen in milder disease. 
The pattern of multiple activation reported by Kuo et al. [19] is reminiscent of the presence of a potential "master regulator," as recently described by CALIFANo and Alvarez [31] in cancer literature. This approach seems to be working for cancer, a disease with a complex genetic background. Thus, it might work for other diseases, such as asthma, in which a multiplicity of genetic signals would have to be coordinated by such master regulators to prompt these proteins to work together to produce a complex effect, as is plausibly occurring in severe asthma. It could be speculated that multiple pathogenic pathways could be triggered by the so-called master regulators that could direct asthma cell behaviour, as they might do in cancer, and provide the starting point for a different approach to drug development. The final aim, of course, is to identify specific clinical and molecular characteristics that could be targeted with specific treatments.

\section{References}

1 Global Initiative for Asthma and Global Initiative for Chronic Obstructive Pulmonary Disease. Global Strategy for Asthma Management and Prevention, 2015. www.ginasthma.org. Date last accessed: January 9, 2017.

2 Reddel HK, Bateman ED, Becker A, et al. A summary of the new GINA strategy: a roadmap to asthma control. Eur Respir J 2015; 46: 622-639.

3 Burrows B, Bloom JW, Traver GA, et al. The course and prognosis of different forms of chronic airways obstruction in a sample from the general population. N Engl J Med 1987; 317: 1309-1314.

4 Chen W, Marra CA, Lynd LD, et al. The natural history of severe asthma and influences of early risk factors: a population-based cohort study. Thorax 2016; 71: 267-275.

5 Hamelmann E, Bernstein JA, Vandewalker M, et al. A randomised controlled trial of tiotropium in adolescents with severe symptomatic asthma. Eur Respir J 2016; 49: 1601100.

6 American Lung Association, Epidemiology and Statistics Unit, Research and Health Education Division. Trends in Mortality and Morbidity, 2012. www.lung.org/finding-cures/our-research/trend-reports/asthma-trend-report.pdf. Date last accessed: January 9, 2017.

7 Camargo CA Jr, Davis KJ, Andrews EB, et al. Pharmacoepidemiological study of long-acting beta-agonist/inhaled corticosteroid therapy and asthma mortality: clinical implications. Clin Drug Investig 2016; 36: 993-999.

8 Fleming L, Murray C, Bansal AT, et al. The burden of severe asthma in childhood and adolescence: results from the paediatric U-BIOPRED cohorts. Eur Respir J 2015; 46: 1322-1333.

9 Bousquet J, Mantzouranis E, Cruz AA, et al. Uniform definition of asthma severity, control, and exacerbations: document presented for the World Health Organization Consultation on Severe Asthma. J Allergy Clin Immunol 2010; 126: 926-938.

10 Bel EH, Sousa A, Fleming L, et al. Diagnosis and definition of severe refractory asthma: an international consensus statement from the Innovative Medicine Initiative (IMI). Thorax 2011; 66: 910-917.

11 Chung KF, Wenzel SE, Brozek JL, et al. International ERS/ATS guidelines on definition, evaluation and treatment of severe asthma. Eur Respir J 2014; 43: 343-373.

12 McDonald VM, Maltby S, Reddel HK, et al. Severe asthma: Current management, targeted therapies and future directions-A roundtable report. Respirology 2017; 22: 53-60.

13 Robinson DS. Assessing severe asthma. Eur Respir J 2016; 48: 611-613.

14 Gaga M, Brand PL, Thomson NC. The quest for the grail: multidimensional efforts for understanding and targeting severe asthma. Eur Respir J 2015; 46: 1227-1231.

15 Lefaudeux D, De Meulder B, Loza MJ, et al. U-BIOPRED clinical adult asthma clusters linked to a subset of sputum omics. J Allergy Clin Immunol 2016; in press [https://doi.org/10.1016/j.jaci.2016.08.048.

16 Loza MJ, Djukanovic R, Chung KF, et al. Validated and longitudinally stable asthma phenotypes based on cluster analysis of the ADEPT study. Respir Res 2016; 17: 165.

17 Moore WC, Fitzpatrick AM, Li X, et al. Clinical heterogeneity in the severe asthma research program. Ann Am Thorac Soc 2013; 10: Suppl, S118-S124.

18 Shaw DE, Sousa AR, Fowler SJ, et al. Clinical and inflammatory characteristics of the European U-BIOPRED adult severe asthma cohort. Eur Respir J 2015; 46: 1308-1321.

19 Kuo CHS, Pavlidis S, Loza M, et al. Th2 and non-Th2 molecular phenotypes of asthma using sputum transcriptomics. Eur Respir J 2017; 49: 1602135.

20 Moore WC, Meyers DA, Wenzel SE, et al. Identification of asthma phenotypes using cluster analysis in the Severe Asthma Research Program. Am J Respir Crit Care Med 2010; 181: 315-323.

21 Haldar P, Pavord ID, Shaw DE, et al. Cluster analysis and clinical asthma phenotypes. Am J Respir Crit Care Med 2008; 178: 218-224.

22 Essat M, Harnan S, Gomersall T, et al. Fractional exhaled nitric oxide for the management of asthma in adults: a systematic review. Eur Respir J 2016; 47: 751-768.

23 Westerhof GA, Korevaar DA, Amelink M, et al. Biomarkers to identify sputum eosinophilia in different adult asthma phenotypes. Eur Respir J 2015; 46: 688-696.

24 de Marco R, Marcon A, Rossi A, et al. Asthma, COPD and overlap syndrome: a longitudinal study in young European adults. Eur Respir J 2015; 46: 671-679.

25 Chung KF. Targeting the interleukin pathway in the treatment of asthma. Lancet 2015; 386: 1086-1096.

26 Ortega H, Chupp G, Bardin P, et al. The role of mepolizumab in atopic and nonatopic severe asthma with persistent eosinophilia. Eur Respir J 2014; 44: 239-241.

27 Fajt ML, Wenzel SE. Development of new therapies for severe asthma. Allergy Asthma Immunol Res 2017; 9: 3-14.

28 Modena BD, Bleecker ER, Busse WW, et al. Gene expression correlated to severe asthma characteristics reveals heterogeneous mechanisms of severe disease. Am J Respir Crit Care Med 2016; in press [https://dx.doi.org/10.1164/ rccm.201607-1407OC].

29 Ray A, Raundhal M, Oriss TB, et al. Current concepts of severe asthma. J Clin Invest 2016; 126: 2394-2403.

30 Wilson SJ, Ward JA, Sousa AR, et al. Severe asthma exists despite suppressed tissue inflammation: findings of the U-BIOPRED study. Eur Respir I 2016; 48: 1307-1319.

31 Califano A, Alvarez MJ. The recurrent architecture of tumour initiation, progression and drug sensitivity. Nat Rev Cancer 2017; 17: 116-130. 